\title{
Nanopore Formation Process in Artificial Cell Membrane Induced by Plasma-Generated Reactive Oxygen Species
}

Ryugo Tero ${ }^{\mathrm{a}, \mathrm{b},{ }^{*}}$, Ryuma Yamashita ${ }^{\mathrm{c}}$, Hiroshi Hashizume ${ }^{\mathrm{d}}$, Yoshiyuki Suda ${ }^{\mathrm{c}}$, Hirofumi Takikawa ${ }^{\mathrm{c}}$, Masaru Hori $^{\text {d }}$, Masafumi Ito ${ }^{\mathrm{e}, *}$

${ }^{a}$ Department of Environmental and Life Sciences, Toyohashi University of Technology, Toyohashi, Aichi 441-8580, Japan

${ }^{\mathrm{b}}$ Electronics-Inspired Interdisciplinary Research Institute, Toyohashi University of Technology, Toyohashi, Aichi 441-8580, Japan

${ }^{c}$ Department of Electrical and Electronic Information Engineering, Toyohashi, Toyohashi University of Technology, Toyohashi, Aichi 441-8580, Japan

${ }^{\mathrm{d}}$ Plasma Medical Science Global Innovation Center, Nagoya University, Nagoya, Aichi 464-8601, Japan

${ }^{\mathrm{e}}$ Department of Electrical and Electronic Engineering, Faculty of Science and Technology, Meijo University, Nagoya, Aichi 468-8502, Japan

* Corresponding authors.

E-mail address: tero@tut.jp (R. Tero), ito@meijo-u.ac.jp (M. Ito)

\begin{abstract}
We investigated morphological change of an artificial lipid bilayer membrane induced by oxygen radicals which were generated by non-equilibrium atmospheric pressure plasma. Neutral oxygen species, $\mathrm{O}\left({ }^{3} \mathrm{P}_{\mathrm{j}}\right)$ and $\mathrm{O}_{2}\left({ }^{1} \Delta_{\mathrm{g}}\right)$, were irradiated of a supported lipid bilayer existing under a buffer solution at various conditions of dose time and distances, at which the dose amounts of the oxygen species were calculated quantitatively. Observation using an atomic force microscope and a fluorescence microscope revealed that dose of the neutral oxygen species generated nanopores with the diameter of $10-50 \mathrm{~nm}$ in a phospholipid bilayer, and finally destructed the bilayer structure. We found that protrusions appeared on the lipid bilayer surface prior to the formation of nanopores, and we attributed the protrusions to the precursor of the nanopores. We propose a mechanism of the pore formation induced by lipid oxidation on the basis of previous experimental and theoretical studies.
\end{abstract}

Keywords: Atmospheric pressure plasma; Lipid bilayer; Lipid oxidation; Reactive oxygen species; Atomic force microscope 


\section{Introduction}

Reactive oxygen species (ROSs) are reactive factors and/or mediators in biological and physiological reactions shown to be either beneficial or harmful [1-3]. Atmospheric pressure plasma is a novel and valuable tool to generate ROSs intentionally, as well as reactive nitrogen species (RNSs) and electric field, and is applied in the fields of medicine and biology in these decades [4-6]. Recent studies demonstrated the multifarious applications of atmospheric pressure plasma in these fields; sterilization [7-13], selective killing of tumor cells $[14,15]$, cellar regulation [16,17], and gene transfection [18,19]. Various kinds of ROS and RNS are generated and included in these reactions induced by atmospheric pressure plasma [12], and play crucial roles in these phenomena. Some studies showed that radical species are requisite for the transportation of materials through a cell membrane $[19,20]$. Recently we developed a neutral oxygen radical source on the basis of non-equilibrium atmospheric pressure plasma [21], which effectively inactivates Penicillium digitatum spores [22-26] and proliferates/inactivates Saccharomyces cerevisiae [27]. This radical source excludes the effects of electric field and lights, and supply only ROSs. The ROSs provided by this radical source are characterized and their dose amounts were quantitatively evaluated [21,25-27]. The active species critical for these reactions are attributed to the atomic oxygen at the ground state $\mathrm{O}\left({ }^{3} \mathrm{P}_{\mathrm{j}}\right)$, and its amount is on the order of $10^{19} \mathrm{~cm}^{-3}$.

In spite of the various applications of the atmospheric pressure plasma, however, what ROSs causes on cell membranes and how ROSs pass through cell membranes are still unclear. Biological cell membrane is the outermost cell organ and acts as a barrier and gate controlling the transportation of materials and information. Everything needs to pass through a cell membrane when it enters into a cell and cause an effect inside the cell. The plasma-generated ROSs also access to the cell membranes first. The critical effect of ROSs on cells may be a direct effect on cell membranes, or indirect one through physiological cascades inside cells and/or genetic damages. Some previous studies showed that cell membranes take damage and act as a barrier against plasma-induced effects on genomic damage or oxidative protein modification [7,28-31], while other studies showed that plasma effects causes the oxidation of the intracellular organelles because of the permeation of ROS through the cell wall and cell membrane, without a major deformation of the membranes [10,15,23-25]. Simple permeation of water-soluble ROSs through a cell membrane is highly unlikely, because the fundamental structure of a cell membrane is a lipid bilayer which has hydrophobic core. Physical damage to a cell membrane, such as poration, is effective for the transportation of water-soluble ROSs into cells, but such a non-selective leakage leads to the loss of membrane potential and is highly toxic for cells [32]. The oxidation of lipid induced by physiological ROSs is also related to cell damages and various pathological states [1-3]. A fundamental understanding of the effects and their mechanism of plasma-induced ROSs on a cell membrane is demanded for the further progress and establishment of safety in the medical and biological application of atmospheric pressure plasma.

Artificial lipid bilayers are biomembrane model systems useful for investigating the fundamental interaction between cell membranes and medical and biological agents [33-38]. Very recently effects of atmospheric pressure plasma irradiation to lipid bilayer membranes have been studied using lipid vesicles (liposomes) [39-44], red blood cell ghost [30], and supported lipid bilayers (SLBs) [45-47]. The studies 
using lipid vesicles showed that plasma-generated ROS and RNS are prevented by the lipid bilayer effectively but partly permeate into the inside of lipid vesicles, while the structural deformation or decomposition of vesicles is limited. Hammers et al. proposed that oxidized lipid in a bilayer membrane apply a mechanical stress which leads to local rupturing of the bilayer [41]. SLB is an artificial planar lipid bilayer system formed at a solid-liquid interface $[34,48,49]$. The SLBs have advantages that fluid and fragile lipid membranes exist stably owing to the support of the solid substrate and that high-resolution surface scientific techniques such as atomic force microscope (AFM) are available. Recently we revealed that irradiation of atmospheric pressure plasma on the basis of dielectric barrier discharge (DBD) reduces the fluidity of a lipid bilayer at the initial stage [46], then generates pores with diameter in the order of 10 $\mathrm{nm}-1 \mu \mathrm{m}$ in the lipid bilayer [45] using the SLB system. We also showed that equilibrium molecules such as hydrogen peroxide $\left(\mathrm{H}_{2} \mathrm{O}_{2}\right)$ and $\mathrm{NO}_{3}{ }^{-}$does not cause these phenomena, and suggested that transient reactive species are responsible for these phenomena, [45]

In this study, we investigated effects of the oxygen radicals generated by non-equilibrium atmospheric pressure plasma on the morphology of SLB. We irradiated neutral oxygen species, $\mathrm{O}\left({ }^{3} \mathrm{P}_{\mathrm{j}}\right)$ and $\mathrm{O}_{2}\left({ }^{1} \Delta_{\mathrm{g}}\right)$ of quantitatively evaluated amounts to SLB existing in a buffer solution [21,25-27]. After the irradiation of $\mathrm{O}\left({ }^{3} \mathrm{P}_{\mathrm{j}}\right)$ and $\mathrm{O}_{2}\left({ }^{1} \Delta_{\mathrm{g}}\right)$, nanopores were observed in SLB with AFM, and SLB was finally decomposed almost completely. AFM observation showed that protrusions appeared on SLB before the nanopore formation. The area fraction and size of the nanopores increased with dose amount of the neutral oxygen species. We propose a mechanism of the morphological change of a lipid bilayer through two-step lipid oxidation on the acyl chain induced by hydroxyl radical.

\section{Experimental}

\section{Irradiation of neutral oxygen radicals to supported lipid bilayer}

Figure 1 shows the schematic of the experimental setup used for the irradiation of the neutral oxygen radicals to a sample cell containing the $\mathrm{SLB}$ on a $\mathrm{SiO}_{2} / \mathrm{Si}$ substrate and a buffer solution, using an atmospheric pressure oxygen radical source. The oxygen radical source (Tough Plasma, Fuji Machine) was based on atmospheric pressure high-density $\mathrm{O}_{2} / \mathrm{Ar}$ plasma, which generates electrons at a density of about $10^{16} \mathrm{~cm}^{-3}$. The details about the radical source is described elsewhere [21,22]. Charged species and optical radiation from the $\mathrm{O}_{2} / \mathrm{Ar}$ plasma were blocked by electrodes and the nozzle aperture of the radical source, so that only neutral species were supplied to the samples. The nozzle of the radical source used in this study had a slit aperture of $0.5 \times 16 \mathrm{~mm}^{2}$, the same as previous studies in Refs. [23,27]. The sample cell was made of a cover glass slip and an O-ring of silicone resin with a thickness of $2 \mathrm{~mm}$, and the volume of the buffer solution in the sample cell was $400 \mu \mathrm{L}$. The irradiation distance $(d)$ from the nozzle of the radical source to the surface of the buffer solution was set at 8,12, 16 or $20 \mathrm{~mm}$. Prior to exposure, the treatment area was purged with the Ar gas from the radical source using a plastic cover, thereby eliminating the influence of atmospheric gases. The oxygen radical treatment was performed at a total flow rate of 5 standard liters per minute $(\mathrm{slm})$ and an $\mathrm{O}_{2} /\left(\mathrm{Ar}+\mathrm{O}_{2}\right)$ flow rate ratio of $0.6 \%$, with treatment time varying from $180 \mathrm{~s}$ to $420 \mathrm{~s}$. After the oxygen radical treatment, we immediately transferred the sample cell to a fluorescence microscope or an atomic force microscope in the same room, and started the 
observation.

\section{Preparation of lipid vesicles and supported lipid bilayer}

Lipid agents in the form of chloroform solution were purchased from Avanti Polar Lipids Inc., and used without further purification. We used 1,2-dioleoyl-sn-glycero-3-phosphocholine (DOPC) because the diacylphosphatidylcholine, a glycerol phospholipid having phosphocoline on its hydrophilic head group, is the representative phospholipid most abundantly existing in cell membranes of Eukaryote. A vacuum-dried film of DOPC mixed with a fluorescence-labeled lipid (1,2-dioleoyl-sn-glycero-3-phosphoethanolamine-N-(lissamine rhodamine B sulfonyl) (Rb-DOPE)) at the molar ratio of 200:1 was prepared from their chloroform solutions, and suspended in a buffer solution (100 $\mathrm{mM} \mathrm{KCl}, 25 \mathrm{mM}$ HEPES/NaOH ( $\mathrm{pH}$ 7.4), chemicals were purchased from Wako Pure Chemical Industries, Ltd.) at the lipid concentration of $0.40 \mathrm{mM}$ to prepare multilamellar vesicles (MLVs). The MLVs were transformed to unilamellar vesicles with an average diameter of $120 \mathrm{~nm}$ through freeze-and-thaw cycles and the extrusion process through a $100 \mathrm{~nm}$-pore polycarbonate filter as described in previous studies [50-52]. The DOPC-SLB containing Rb-DOPE was prepared on thermally oxidized $\mathrm{SiO}_{2} / \mathrm{Si}$ substrates by the vesicle fusion method [34]. A thermally oxidized $\mathrm{SiO}_{2} / \mathrm{Si}$ substrate $\left(8 \times 8 \mathrm{~mm}^{2}\right.$, $0.525 \mathrm{~mm}$ thick) was incubated in the vesicle suspension at $45^{\circ} \mathrm{C}$ for $1 \mathrm{~h}$. We exchanged the vesicle suspension with the buffer solution 10 times after the incubation to remove excess vesicles in the aqueous phase. Our preparation method provides uniform DOPC-SLB on whole the substrate surface reproducibly as we show in previous studies $[34,45,46,50-55]$.

\section{Atomic force microscope and fluorescence microscope}

The SLBs were observed with an AFM (PicoPlus 5500, Agilent Technologies, Inc., formerly Molecular Imaging, Corp.), and an epi-fluorescence microscope (BX51WI, Olympus). We adopted acoustic AC mode (tapping mode) for the AFM observation using a $\mathrm{Si}_{3} \mathrm{~N}_{4}$ cantilever $(2 \mathrm{~N} / \mathrm{m}$, tip curvature radius of $10 \mathrm{~nm}$ ). We used a high-pressure mercury lump and neutral density (ND) filters for the fluorescence observation, and irradiated brighter excitation light by removing the ND filters for the observation of fluorescence recovery after photobleaching (FRAP) process $[51,52,55]$. We kept the SLB samples under the buffer solution during the all processes of the preparation, plasma irradiation, and observations. We used Image $\mathrm{J}$ software ( $\mathrm{NIH}$, http://imagej.nih.gov/ij/) for the analysis of AFM topographies. The area fraction and density of objects were evaluated as the average of at least three images for each experimental condition.

\section{Results}

Figure 2a shows the AFM topographies of DOPC-SLB on the thermally oxidized $\mathrm{SiO}_{2} / \mathrm{Si}$ surface. The sample was settled under the $\mathrm{O}_{2}+$ Ar gas flow for $300 \mathrm{~s}$ without generating plasma. The SLB had uniform and flat surface with the roughness of $0.23 \mathrm{~nm}(\mathrm{rms})$ as with our previous studies $[45,52,53]$. Therefore the $\mathrm{O}_{2}+\mathrm{Ar}$ gas flow did not affect the morphology of SLB. After the irradiation of neutral oxygen radicals induced by atmospheric plasma at $d=8 \mathrm{~mm}$ for $300 \mathrm{~s}$, pores appeared in the SLB (Fig. 
$2 \mathrm{~b})$. The diameter of the pores was $20.8 \pm 3.9 \mathrm{~nm}$, and area fraction was $1.39 \%$. The depth of the pores was approximately $2 \mathrm{~nm}$. We also found some protrusions with the height of $5-6 \mathrm{~nm}$, but its density was smaller than the nanopores. In the phase-shift image, which is the mapping of viscoelasticity, the edge of the nanopores had clear contrast compared with the flat SLB (Fig. 2c). Thickness of lipid bilayers is approximately $5 \mathrm{~nm}[52,56,57]$, and the nanopores in this study were observed shallower similar to our previous study [45]. One possibility is that the tip of the cantilever did not reach to the bottom of the pore, because the curvature radius of the cantilever is $10 \mathrm{~nm}$ as a nominal value before use. It may be also partly because of different hydrophilicity of the inside of nanopore due to some residual lipids from outside of the nanopores, artificial height appears in AFM topographies on a hydrophobic sample in an aqueous solution [57]. We note that the morphological change in DOPC-SLB such as protrusion and pores were observed from the first image after the oxygen plasma treatment. Thus the morphological change occurred during the oxygen plasma irradiation.

We observed the macroscopic morphological change using a fluorescence microscope (Fig. 3). The DOPC-SLB containing $0.2 \%$ of Rb-DOPE without the irradiation of neutral oxygen radicals was observed as a homogeneous membrane (Fig. 3a). Fluorescence recovery after photobleaching (FRAP) method [51,52] showed the fluidity and continuity of SLB (data not shown). After the irradiation of the oxygen radicals at $d=8 \mathrm{~mm}$ for $300 \mathrm{~s}$, which was the same condition as Fig. 2b, we did not find a clear difference in the fluorescence image (Fig. 3b) from that before the radical irradiation (Fig. 3a). It should be noted that the size of the pores observed in the AFM topography in Fig. $2 b$ was smaller than the resolution limit of an optical microscope using visible light. Thus the nanopores also existed in the SLB shown in Fig. 3b. Pores on the order of micrometers, which appear after the irradiation of DBD-plasma [45], were not observed in this study. After the irradiation of oxygen radicals at $d=8 \mathrm{~mm}$ for $420 \mathrm{~s}$, the fluorescence signal from the DOPC-SLB almost disappeared (Fig. 3c). The result indicates that bilayer structure was deconstructed and majority of the DOPC-SLB was removed from the substrate. Nanopores of $\sim 20 \mathrm{~nm}$ shown in Fig. 2 are large enough for the transportation of not only ROS/RNS species but also for larger molecules like DNA even if they are short-lived, and are fatal for living cell if they exist stable [32]. What important in the field of plasma medicine are these transportation phenomena and their mechanism, not the complete removal of membranes. Therefore we focus on the formation process of the nanopores in this study, and do not intend further step for the membrane destruction.

We investigated the formation process of the nanopores observed in Fig. $2 b$ induced by the irradiation of the neutral oxygen radicals. Figure 4 shows the dependence of the DOPC-SLB morphology on the irradiation time at a fixed irradiation distance of $d=8 \mathrm{~mm}$. We found that protrusions appeared on the DOPC-SLB surface after the irradiation for $180 \mathrm{~s}$ (Fig 4a). The height of the protrusion was approximately $5-6 \mathrm{~nm}$, similar to that observed in Fig. $2 \mathrm{~b}$. The density of the protrusion was $22.3 \mu \mathrm{m}^{-2}$. Small pores with the average diameter of $16.6 \pm 3.7 \mathrm{~nm}$ also existed, and their area fraction was $0.93 \%$. The protrusions were rarely observed after longer irradiation times (Fig. 4b: 240 s, and Fig. 4c: 300 s). The average diameter of the pores in Fig. $4 \mathrm{~b}$ was $18.7 \pm 5.5 \mathrm{~nm}$, and the area fraction of the pores was $1.93 \%$. Clear contrast at the pore edge was observed in the phase-shift image as in Fig. 2c. These results indicate that the protrusions observed in Fig. 4a were the precursor of the nanopores which were produced by the 
plasma-generated oxygen species.

Figure 5 shows the dependence of the pore formation on the irradiation distance $d$. Figure $5 \mathrm{a}-\mathrm{c}$ show the DOPC-SLB irradiated at $d=12 \mathrm{~mm}, 16 \mathrm{~mm}$, and $20 \mathrm{~mm}$, respectively, at the fixed irradiation time of $420 \mathrm{~s}$. At this irradiation time, the bilayer structure was destructed in case the irradiation distance was $d=$ $8 \mathrm{~mm}$ (Fig. 3c). Figure 5a shows the AFM topography of the DOPC after the irradiation at $d=12 \mathrm{~mm}$. DOPC-SLB existed and nanopores of $15.6 \pm 2.3 \mathrm{~nm}$ in diameter were observed. The area fraction of the pores was $1.92 \%$. We also confirmed the existence of the DOPC-SLB by epi-FM (data not shown). At $d=$ $16 \mathrm{~mm}$, pores $46.0 \pm 6.5 \mathrm{~nm}$ were observed (Fig. $5 \mathrm{~b}$ ), and the area fraction was $1.76 \%$. At $d=20 \mathrm{~mm}$, we did not found a pore in the SLB (Fig. 5c), and recognized a few protrusions. The results in Fig. 5 and Fig. $3 \mathrm{c}$ revealed that the rate of pore formation was attenuated depending on $d$, while the diameter of nanopores did not simply attenuate with $d$.

\section{Discussion}

Recently we reported that DBD plasma irradiation generated pores in the DOPC-SLB, and attributed the active species responsible for the nanopore formation to transient ROS species, rather than equilibrium molecules such as $\mathrm{H}_{2} \mathrm{O}_{2}$ and $\mathrm{NO}_{3}{ }^{-}$[45]. The results in the present study (Figs. 2 - 5) certify oxygen radicals were crucial for the morphological change and pore formation in SLB, because the oxygen radical source in this study provides ground-state atomic oxygen $\left(\mathrm{O}\left({ }^{3} \mathrm{P}_{\mathrm{j}}\right)\right)$, singlet oxygen molecule $\left(\mathrm{O}_{2}\left({ }^{1} \Delta_{\mathrm{g}}\right)\right)$ and trace amount of ozone $\left(\mathrm{O}_{3}\right)$ isolating the effects of UV light and electric fields [21,22,25-27]. Excited argon atoms are also generated, but their oxidation activity is negligible [21,22]. Therefore the morphological changes observed in this study are because of the oxidation of lipid. The $\mathrm{O}\left({ }^{3} \mathrm{P}_{\mathrm{j}}\right)$ from the gas phase generates hydroxyl radical $(\cdot \mathrm{OH})$ and $\mathrm{H}_{2} \mathrm{O}_{2}$ as follows [27]:

$$
\begin{aligned}
& \mathrm{O}\left({ }^{3} \mathrm{P}_{\mathrm{j}}\right)+\mathrm{H}_{2} \mathrm{O} \rightarrow \cdot \mathrm{OH}+\cdot \mathrm{OH}, \\
& \cdot \mathrm{OH}+\cdot \mathrm{OH} \rightarrow \mathrm{H}_{2} \mathrm{O}_{2} .
\end{aligned}
$$

$\mathrm{O}_{2}\left({ }^{1} \Delta_{\mathrm{g}}\right)$ turns to triplet oxygen molecule when it meets $\mathrm{H}_{2} \mathrm{O}$. Therefore the active oxygen species generated from $\left.\mathrm{O}^{3} \mathrm{P}_{\mathrm{j}}\right)$ are mainly $\cdot \mathrm{OH}$ and $\mathrm{H}_{2} \mathrm{O}_{2}$, and $\mathrm{O}_{2}\left({ }^{1} \Delta_{\mathrm{g}}\right)$ provided dissolved $\mathrm{O}_{2}$ in the buffer solution. A part of $\mathrm{O}\left({ }^{3} \mathrm{P}_{\mathrm{j}}\right)$ turns to $\mathrm{O}_{3}$ in gas phase through the three-body reaction with $\mathrm{O}_{2}$ depending on the distance from the source nozzle. The density of $\mathrm{O}_{3}$ might be comparable to that of $\mathrm{O}\left({ }^{3} \mathrm{P}_{\mathrm{j}}\right)$, but is still below the detection limit in excessive amount of Ar as shown in our previous study [26]. It is possible that this trace amount of $\mathrm{O}_{3}$ also partly contributed to the generation of $\cdot \mathrm{OH}$, because it is well known that $\mathrm{O}_{3}$ forms $\cdot \mathrm{OH}$ in aqueous solution $[58,59]$. The dose amounts to the buffer solution in this study $(400 \mu \mathrm{L})$ at the conditions in Figs. 2-5 were calculated on the basis of the previous study [27] and summarized in Table 1 and Table 2 accompanied with the average diameter and area fraction of the nanopores and the density of the protrusion observed in the AFM images in Figs. 2, 4 and 5. When the irradiation time was varied keeping $d$ constant (Table 1), the dose amount of $\mathrm{O}\left({ }^{3} \mathrm{P}_{\mathrm{j}}\right)$ and $\mathrm{O}_{2}\left({ }^{1} \Delta_{\mathrm{g}}\right)$ increases with time linearly at the same ratio between $\mathrm{O}\left({ }^{3} \mathrm{P}_{\mathrm{j}}\right)$ and $\mathrm{O}_{2}\left({ }^{1} \Delta_{\mathrm{g}}\right)$. On the other hand, the ratio of $\mathrm{O}\left({ }^{3} \mathrm{P}_{\mathrm{j}}\right)$ to $\mathrm{O}_{2}\left({ }^{1} \Delta_{\mathrm{g}}\right)$ decreases with $d$ (Table 2).

The oxidation of lipids by ROSs under physiological condition proceeds at $\mathrm{C}=\mathrm{C}$ bonds of acyl chains 
through two steps [2,3]: peroxidation producing hydroperoxidized lipid, and truncation resulting in a truncated-chain lipid which is terminated with aldehyde (or carboxyl) groups and fragmented fatty aldehyde (Fig. 6). Hydroxyl radical $(\cdot \mathrm{OH})$ gives rise to primary stage of lipid hydroperoxidation generating a lipid radical, and the lipid radical triggers the peroxidation of the acyl chains of lipids which is a chain reaction consuming oxygen molecule [2,3]:

$$
\begin{aligned}
& \cdot \mathrm{OH}+\text { Lipid } \rightarrow \mathrm{H}_{2} \mathrm{O}+\cdot \text { Lipid (lipid radical), } \\
& \cdot \text { Lipid }+\mathrm{O}_{2} \rightarrow \text { Lipid-OO } \text { (peroxy lipid radical), } \\
& \text { Lipid-OO }+ \text { Lipid } \rightarrow \text { Lipid-OOH }+\cdot \text { Lipid. }
\end{aligned}
$$

The truncation of the peroxidized acyl chain proceeds the intramolecular radical transfer of peroxy lipid radical instead of the intermolecular transfer (eq. (5)), or a Hock-type cleavage reaction of hydroperoxy lipid [2]. Therefore the lipid oxidation in this study is initiated by $\cdot \mathrm{OH}$ generated from $\mathrm{O}\left({ }^{3} \mathrm{P}_{\mathrm{j}}\right.$ ) (eq. (1)) following eq. (3). Various kinds of radical and ionic species are possibly generated from $\mathrm{O}\left({ }^{3} \mathrm{P}_{\mathrm{j}}\right)$ in aqueous phase, but we focus on $\cdot \mathrm{OH}$ because it is crucial for the oxidation of lipids at acyl chains [2,3]. The advantage of artificial lipid membrane system in this study is that the reactant is a pure lipid and well-characterized oxygen species were provided, thus we can reasonably assume that reaction proceeds ideally compared to other biological systems such as cells in culturing media.

We suppose that $\cdot \mathrm{OH}$ is transported to SLB through the buffer solution by a flow in the solution induced by gas flow from the radical source, rather than by simple thermal diffusion. Previous studies showed that ROSs including $\cdot \mathrm{OH}$ with significant amount for oxidative reaction circulate in an aqueous solution under the existence of gas flow [60-62], in spite of the short life time of $\cdot \mathrm{OH}$, approximately 200 $\mu$ s in an aqueous phase [27]. We emphasize that $\cdot \mathrm{OH}$ works as the initiator of the chain reaction (eq. 3), and stoichiometric amount of $\cdot \mathrm{OH}$ to lipid molecules is not necessary. We estimate the amount of lipid molecules desorbed from SLB on the basis of typical occupying area of one DOPC molecule in a bilayer, $0.64 \mathrm{~nm}$ [56]. Area fraction of $2 \%$ in a bimolecular membrane on a substrate $\left(8 \times 8 \mathrm{~mm}^{2}\right)$ corresponded to $4 \times 10^{12}$ molecules $=6.6 \times 10^{-12}$ mol. It may be an overestimation as the amount of oxidized lipid, because it is possible that some non-oxidized lipids are incorporated in desorbed micelles. Singlet oxygen $\mathrm{O}_{2}\left({ }^{1} \Delta_{\mathrm{g}}\right)$ does not cause the oxidation of lipid directly in the buffer solution, but assists the lipid oxidation by supplying oxygen molecule to the lipid bilayer through the buffer solution for the chain reaction (eqs. (4) and (5)), which leads to the truncation of acyl chains. Inclusion of hydroperoxidized lipid, the product of the first step of the oxidation process in Fig. 6, into a lipid bilayer reduces the fluidity of membrane [41,63-65]. On the other hand truncated-chain lipids increase the fluidity of membrane [64-66]. Previously we reported the reduction of fluidity of DOPC-SLB by the DBD-based plasma irradiation before the generation pores using fluorescence recovery after photobleaching (FRAP) method [46]. Thus the pore formation in DOPC-SLB (Figs. 2, 4 and 5) is caused by the truncation of lipid, the second step of the lipid oxidation process (Fig. 6), rather than the hydroperoxidized lipid. Our previous studies also showed that $\mathrm{H}_{2} \mathrm{O}_{2}$, which was also produced in this study by the recombination of $\cdot \mathrm{OH}$ (eq. (2)), causes neither the pore formation or reduction of fluidity in DOPC-SLB $[45,46]$.

The results in Fig. 4 and Table 1 show the time course of the pore formation, at the constant $\mathrm{O}\left({ }^{3} \mathrm{P}_{\mathrm{j}}\right)$ to $\mathrm{O}_{2}\left({ }^{1} \Delta_{\mathrm{g}}\right)$ ratio, thus we reasonably assume the constant $\cdot \mathrm{OH}$ to $\mathrm{O}_{2}$ ratio in the buffer solution. Prior to the 
nanopore formation, protrusions appeared as shown in Fig. 4a (180 s). We attribute the protrusion to the fragmented fatty aldehyde accumulated in the hydrophobic core of the lipid bilayer. Truncated-chain lipid, the other product of the fragmentation, bends its aldehyde-terminated shorter acyl chain toward the aqueous phase [64,65], and behaves like a detergent with a larger hydrophilic head group. As explained from the critical packing parameter [67], the truncated-chain lipids which have packing parameter less than 1 because of its relatively large hydrophilic head compared with hydrophobic tail, form micelle in aqueous phase [65]. Therefore the truncated-chain lipids desorb from the lipid bilayer after their concentration increases by the further irradiation of $\cdot \mathrm{OH}$ and $\mathrm{O}_{2}$, leaving pores in the bilayer (Figs. $4 \mathrm{~b}$ (240 s) and 4c (300 s)). Recent study by molecular dynamic simulation indicates that formation and desorption of "hydrophobic droplet" from a massively oxidized DOPC bilayer consisting of truncated-chain lipid and fragmented fatty aldehyde [68]. A lipid bilayer membrane is a flexible material, and the volume of the protrusions, corresponding to an area fraction of a few percent, is reasonably supplied by stretching the surrounding membrane slightly. Formation of defects or cracks exposing the hydrophobic region to an aqueous phase is energetically more unfavorable than stretching the bilayer membrane retaining the bilayer structure. On the other hand, the truncated-chain lipid stabilizes the edge of the pores forming a hemimicelle. It is reasonable that the pore edge gave clear contrast in the phase-shift images in Fig. 2c and Fig. $4 \mathrm{~b}$ if the density of truncated-chain lipid is higher at the pore edge than the surrounding SLB still rich in non-oxidized lipid. Further incorporation of the truncated-chain lipid and the fatty aldehyde into SLB accelerates desorption of micelles and finally destructs the bilayer structure (Fig. 3c (420 s)). Previous study indicated that the threshold concentration of the deconstruction of bilayer structure is above $10 \%$ [69].

The results in Fig. 5 and Table 2 shows the dependence of nanopore formation on the irradiation distance $d$ indicating the effect of the dose ratio between $\cdot \mathrm{OH}$ and $\mathrm{O}_{2}$. The dose amount of $\cdot \mathrm{OH}$, which is generated from $\mathrm{O}\left({ }^{3} \mathrm{P}_{\mathrm{j}}\right)$ (eq. (1)) decreases with $d$ while that of $\mathrm{O}_{2}$, resulting from $\mathrm{O}_{2}\left({ }^{1} \Delta_{\mathrm{g}}\right)$ (eq. (2)), increases. It means that the frequency of trigger reaction (eq. (3)) decreases with $d$, while $\mathrm{O}_{2}$ for chain reaction (eqs. (4) and (5)) are provided sufficiently. As shown in Fig. 5, the number density of nanopore decreased with $d$. The smaller number of nanopores grew larger in Fig. $5 \mathrm{~b}(d=16 \mathrm{~mm})$ than those in Fig. $5 \mathrm{a}(d=12 \mathrm{~mm})$. Figure $5 \mathrm{c}$, and also Fig. $2 \mathrm{a}$, shows that $\cdot \mathrm{OH}$ is requisite for the formation of nanopore, and providing $\mathrm{O}_{2}$ only is not sufficient.

We summarize the mechanism of the pore formation caused by the plasma-generated neutral oxygen species in Fig. 7:

(1) $\mathrm{O}\left({ }^{3} \mathrm{P}_{\mathrm{j}}\right)$ and $\mathrm{O}_{2}\left({ }^{1} \Delta_{\mathrm{g}}\right)$ from gas phase turns to $\cdot \mathrm{OH}$ and $\mathrm{O}_{2}$, respectively, in the buffer solution.

(2) $\cdot \mathrm{OH}$ and $\mathrm{O}_{2}$ oxidize lipid on its unsaturated bond: $\cdot \mathrm{OH}$ initiates the reaction by producing a lipid radical, and $\mathrm{O}_{2}$ propagates the generation of lipid hydroperoxide followed by fragmentation to truncated-chain lipid and fatty aldehyde (Fig. 6).

(3) Fatty aldehyde is accumulated in the hydrophobic core of the lipid bilayer forming a protrusion. Positive curvature of the protrusion is assisted by the truncated-chain lipid.

(4) After the concentration of the truncated-chain lipid in a lipid bilayer increases, truncated-chain lipids form a micelle and desorb to the aqueous phase accompanying with fatty aldehyde. 
(5) A part of the truncated-chain lipid remaining in the lipid bilayer stabilizes the edge of a pore in the lipid bilayer forming hemi-micelle.

We propose these processes on the basis of the previous experimental and theoretical studies as discussed above. It is reasonable that the diameter of pore or area fraction did not show simple linear dependence on the dose of $\mathrm{O}\left({ }^{3} \mathrm{P}_{\mathrm{j}}\right)$, which provides $\cdot \mathrm{OH}$, because stoichiometric $\cdot \mathrm{OH}$ is not necessary for the oxidation of lipid as we discussed above.

The significant difference of the plasma-induced reaction from reactions induced by physiological ROSs is that the rapid increase in the density of ROS. The radical source in this study effectively provides ROSs on the order of $10^{19} \mathrm{~cm}^{-3}$ is supplied in a few minutes by the radical source in this study [27]. Rapid and local accumulation of the products of lipid oxidation, such as protrusions of fatty aldehyde (Fig. 4a) and truncated-chain lipid at the nanopore edge (Fig. 2c and Fig. 4b), are necessary for the pore formation, because lipid molecules diffuse laterally in a bilayer. We note that pores in a lipid bilayer is energetically unfavorable even though the pore edge is capped with a hemimicelle, and the nanopores stably existed because we used the SLB system [34]. The life time of nanoscale pores is short in free-standing membranes like liposomes or in living cells, but anyway a channel through a lipid bilayer opens. $\mathrm{H}_{2} \mathrm{O}_{2}$ is transported into cells by some kinds of aquaporins, water channel proteins [70], and induces apotosis or hinders the growth of living cells [71-73]. Plasma-generated $\mathrm{H}_{2} \mathrm{O}_{2}$ (eq. (2)) does not affect the structure and fluidity of a lipid bilayer membrane $[45,46]$, but the plasma-generated nanopores open an additional pathway for the transportation of $\mathrm{H}_{2} \mathrm{O}_{2}$. It is also known that oxidized lipids act as mediators stimulating various physiological cascades [2,3]. The morphological change of DOPC-SLB by the plasma-induced lipid oxidation in this study provides information for the fundamental understanding of the effects of atmospheric pressure plasma to cell membranes.

\section{Conclusion}

Neutral oxygen species $\left(\mathrm{O}\left({ }^{3} \mathrm{P}_{\mathrm{j}}\right)\right.$ and $\left.\mathrm{O}_{2}\left({ }^{1} \Delta_{\mathrm{g}}\right)\right)$, which were generated by atmospheric pressure plasma, caused the formation of the protrusion and nanopores in the supported lipid bilayer of phosphatidylcholine in a buffer solution. AFM topographies revealed that the protrusions appeared at low dose amount of $\mathrm{O}\left({ }^{3} \mathrm{P}_{\mathrm{j}}\right)$ and the nanopores appeared at high dose. We attributed the morphological change to the accumulation of the products of lipid oxidation, truncated-chain lipid and fatty aldehyde: the truncated-chain lipid forms a micelle including fatty aldehyde, desorbs to aqueous phase leaving a nanopore, and also stabilizes the pore edge by capping with a hemimicelle.

\section{Acknowledgements}

This work was supported by JSPS KAKENHI Grant Numbers 15H00893, 26286072, 24110708, 21110006, 26630156, 15H03768 (especially the Grants-in-Aid for Scientific Research on Innovative Areas, "Frontier Science of Interactions between Plasmas and Nano-interfaces" [21110006, 24110708] and "Plasma Medical Innovation" [15H00893]), Foundation for Opto-Science and Technology, the Naito Research 
Grant, and CREST, JST. We also acknowledge the support from the EIIRIS Project from Toyohashi University of Technology and the project for promoting Research Center in Meijo University. 
Table 1. Dependence on irradiation time $(d=8 \mathrm{~mm})$ : Summary of the irradiation time, dose amount and the results obtained from the AFM topographies Fig. 2b and Fig. 4.

\begin{tabular}{cccccc}
\hline \multicolumn{2}{c}{ Irradiation time $(\mathrm{s})$} & 180 & 240 & 300 & 420 \\
\hline Dose amount & $\mathrm{O}\left({ }^{3} \mathrm{P}_{\mathrm{j}}\right)$ & 17.0 & 22.7 & 28.3 & 39.7 \\
$\left(10^{18} \mathrm{~cm}^{-3}\right)^{*}$ & $\mathrm{O}_{2}\left({ }^{1} \Delta_{\mathrm{g}}\right)$ & 25.5 & 33.9 & 42.4 & 59.4 \\
\hline \multicolumn{2}{l}{ Diameter of pore $(\mathrm{nm})$} & $16.6 \pm 3.7$ & $18.7 \pm 5.5$ & $20.8 \pm 3.9$ & SLB was \\
Area fraction of pore $(\%)$ & 0.93 & 1.93 & 1.39 & deconstructed \\
\multicolumn{2}{l}{ Density of protrusion $\left(\mu \mathrm{m}^{-2}\right)$} & 22.3 & Not found & 1.3 & \\
\hline
\end{tabular}

$*$ Calculated on the basis of ref. [27].

Table 2. Dependence on irradiation distance (irradiation time was 420 s): Summary of the irradiation distance, dose amount and the results obtained from the AFM topographies in Fig. 5.

\begin{tabular}{|c|c|c|c|c|}
\hline \multicolumn{2}{|c|}{ Irradiation distance (mm) } & 12 & 16 & 24 \\
\hline \multirow{2}{*}{$\begin{array}{l}\text { Dose amount } \\
\left(10^{18} \mathrm{~cm}^{-3}\right)^{*}\end{array}$} & $\mathrm{O}\left({ }^{3} \mathrm{P}_{\mathrm{j}}\right)$ & 12.5 & 3.96 & 1.25 \\
\hline & $\mathrm{O}_{2}\left({ }^{1} \Delta_{\mathrm{g}}\right)$ & 63.8 & 68.4 & 73.5 \\
\hline \multicolumn{2}{|c|}{ Diameter of pore (nm) } & $15.6 \pm 2.3$ & $46.0 \pm 6.5$ & \multirow{2}{*}{ Not found } \\
\hline \multicolumn{2}{|c|}{ Area fraction of pore $(\%)$} & 1.92 & 1.76 & \\
\hline \multicolumn{2}{|c|}{ Density of protrusion $\left(\mu \mathrm{m}^{-2}\right)$} & Not found & Not found & 0.6 \\
\hline
\end{tabular}

* Calculated on the basis of ref. [27]. 


\section{Figure Captions}

Fig. 1. Schematic of the experimental setup: neutral oxygen radicals were irradiated to a sample cell containing a buffer solution and DOPC-SLB on a $\mathrm{SiO}_{2} / \mathrm{Si}$ substrate at the irradiation distance $(d)$.

Fig. 2. AFM images $\left(1.0 \times 1.0 \mu \mathrm{m}^{2}\right)$ of DOPC-SLB without and with the irradiation of neutral oxygen radicals: (a) AFM topography. $\mathrm{O}_{2}+$ Ar gas was dosed without plasma generation; (b) AFM topography. plasma-generated neutral oxygen species were irradiated of DOPC-SLB through the buffer solution at $d=$ $8 \mathrm{~mm}$ for $300 \mathrm{~s}$. Cross section profiles at the white lines are also shown; (c) Phase-shift image simultaneously obtained with (b). The inset is the magnified image of the region indicated by the dotted square $\left(180 \times 180 \mathrm{~nm}^{2}\right)$.

Fig. 3. Fluorescence microscope images of DOPC-SLB: (a) before the irradiation of neutral oxygen species; (b) after irradiation at $d=8 \mathrm{~mm}$ for $300 \mathrm{~s}$; (c) after irradiation at $d=8 \mathrm{~mm}$ for $420 \mathrm{~s}$.

Fig. 4. AFM topographies of DOPC-SLB irradiated of the neutral oxygen species for various irradiation time at a fixed irradiation distance $d=8 \mathrm{~mm}$ : (a) $180 \mathrm{~s}$. Cross section profile at the white line is also shown; (b) $240 \mathrm{~s}$. The lower image is the simultaneously obtained phase-shift image at the region indicated by the dotted square $\left(150 \times 150 \mathrm{~nm}^{2}\right)$; (c) $300 \mathrm{~s}$.

Fig. 5. AFM topographies of DOPC-SLB irradiated by the neutral oxygen radicals at various irradiation distance $d$ for $420 \mathrm{~s}$ : (a) $d=12 \mathrm{~mm}$; (b) $d=16 \mathrm{~mm}$; (c) $d=20 \mathrm{~mm}$.

Fig. 6. Two-step oxidation process of phosphatidylcholine molecule at its unsaturated acyl chains. First step: hydroperoxidation at double bond. The head group and the other acyl chain are omitted for the sake of simplicity. Second step: truncation of acyl chains resulting in formation of fragmented fatty aldehyde.

Fig. 7. Scheme of the morphological change of a lipid bilayer membrane caused by the irradiation of plasma-generated active neutral oxygen species. 


\section{References}

[1] L. Zuo, T. Zhou, B.K. Pannell, A.C. Ziegler, T.M. Best, Biological and physiological role of reactive oxygen species - the good, the bad and the ugly, Acta Physiol. 214 (2015) 329-348. doi:10.1111/apha.12515.

[2] H. Yin, L. Xu, N.A. Porter, Free radical lipid peroxidation: mechanisms and analysis., Chem. Rev. 111 (2011) 5944-72. doi:10.1021/cr200084z.

[3] S.S. Davies, L. Guo, Lipid peroxidation generates biologically active phospholipids including oxidatively N-modified phospholipids., Chem. Phys. Lipids. 181 (2014) 1-33. doi:10.1016/j.chemphyslip.2014.03.002.

[4] A. Fridman, G. Friedman, Plasma Medicine, John Wiley \& Sons, Inc., Hoboken, NJ, USA, 2013. doi:10.1002/9781118437704.

[5] T. von Woedtke, S. Reuter, K. Masur, K.-D. Weltmann, Plasmas for medicine, Phys. Rep. 530 (2013) 291-320. doi:10.1016/j.physrep.2013.05.005.

[6] R. Hatakeyama, T. Kaneko, Nano-Bio Fusion Science Opened and Created with Plasmas, Plasma Fusion Res. 6 (2011) 1106011-1106011. doi:10.1585/pfr.6.1106011.

[7] J.H. Park, N. Kumar, D.H. Park, M. Yusupov, E.C. Neyts, C.C.W. Verlackt, et al., A comparative study for the inactivation of multidrug resistance bacteria using dielectric barrier discharge and nano-second pulsed plasma, Sci. Rep. 5 (2015) 13849. doi:10.1038/srep13849.

[8] A. Balasundaram, I. Alexeff, R.S. Sawhney, Design of Experiment-based Testing of Air, Charged Ions, and Hydrogen Peroxide in a Direct Current Steady-State Plasma Sterilizer, Plasma Med. 1 (2011) 179-189. doi:10.1615/PlasmaMed.2012002455.

[9] S. Shimizu, S. Barczyk, P. Rettberg, T. Shimizu, T. Klaempfl, J.L. Zimmermann, et al., Cold atmospheric plasma - A new technology for spacecraft component decontamination, Planet. Space Sci. 90 (2014) 60-71. doi:10.1016/j.pss.2013.10.008.

[10] S. Ikawa, K. Kitano, S. Hamaguchi, Effects of $\mathrm{pH}$ on Bacterial Inactivation in Aqueous Solutions due to Low-Temperature Atmospheric Pressure Plasma Application, Plasma Process. Polym. 7 (2010) 33-42. doi:10.1002/ppap.200900090.

[11] E. Takai, S. Ikawa, K. Kitano, J. Kuwabara, K. Shiraki, Molecular mechanism of plasma sterilization in solution with the reduced $\mathrm{pH}$ method: importance of permeation of HOO radicals into the cell membrane, J. Phys. D. Appl. Phys. 46 (2013) 295402. doi:10.1088/0022-3727/46/29/295402.

[12] K. Oehmigen, J. Winter, M. Hähnel, C. Wilke, R. Brandenburg, K.-D. Weltmann, et al., Estimation of Possible Mechanisms of Escherichia coli Inactivation by Plasma Treated Sodium Chloride Solution, Plasma Process. Polym. 8 (2011) 904-913. doi:10.1002/ppap.201000099.

[13] S. Kumagai, C. Chang, J. Jeong, M. Kobayashi, T. Shimizu, M. Sasaki, Development of plasma-on-chip: Plasma treatment for individual cells cultured in media, Jpn. J. Appl. Phys. 55 (2016) 01AF01. doi:10.7567/JJAP.55.01AF01.

[14] S. Iseki, K. Nakamura, M. Hayashi, H. Tanaka, H. Kondo, H. Kajiyama, et al., Selective killing of ovarian 
cancer cells through induction of apoptosis by nonequilibrium atmospheric pressure plasma, Appl. Phys. Lett. 100 (2012) 113702. doi:10.1063/1.3694928.

[15] K. Panngom, K.Y. Baik, M.K. Nam, J.H. Han, H. Rhim, E.H. Choi, Preferential killing of human lung cancer cell lines with mitochondrial dysfunction by nonthermal dielectric barrier discharge plasma., Cell Death Dis. 4 (2013) e642. doi:10.1038/cddis.2013.168.

[16] F. Mwale, H.T. Wang, V. Nelea, L. Luo, J. Antoniou, M.R. Wertheimer, The effect of glow discharge plasma surface modification of polymers on the osteogenic differentiation of committed human mesenchymal stem cells., Biomaterials. 27 (2006) 2258-64. doi:10.1016/j.biomaterials.2005.11.006.

[17] A. Ando, T. Asano, M.A. Sayed, R. Tero, K. Kitano, T. Urisu, et al., Extracellular Matrix Patterning for Cell Alignment by Atmospheric Pressure Plasma Jets, Jpn. J. Appl. Phys. 51 (2012) 036201. doi:10.1143/JJAP.51.036201.

[18] Y. Ogawa, N. Morikawa, A. Ohkubo-Suzuki, S. Miyoshi, H. Arakawa, Y. Kita, et al., An epoch-making application of discharge plasma phenomenon to gene-transfer, Biotechnol. Bioeng. 92 (2005) 865-870. doi:10.1002/bit.20659.

[19] M. Jinno, Y. Ikeda, H. Motomura, Y. Kido, K. Tachibana, S. Satoh, The Necessity of Radicals for Gene Transfection by Discharge Plasma Irradiation, J. Photopolym. Sci. Technol. 27 (2014) 399-404. doi:10.2494/photopolymer.27.399.

[20] T. Kaneko, S. Sasaki, Y. Hokari, S. Horiuchi, R. Honda, M. Kanzaki, Improvement of cell membrane permeability using a cell-solution electrode for generating atmospheric-pressure plasma, Biointerphases. 10 (2015) 029521. doi:10.1116/1.4921278.

[21] M. Iwasaki, H. Inui, Y. Matsudaira, H. Kano, N. Yoshida, M. Ito, et al., Nonequilibrium atmospheric pressure plasma with ultrahigh electron density and high performance for glass surface cleaning, Appl. Phys. Lett. 92 (2008) 081503. doi:10.1063/1.2885084.

[22] S. Iseki, H. Hashizume, F. Jia, K. Takeda, K. Ishikawa, T. Ohta, et al., Inactivation of Penicillium digitatum Spores by a High-Density Ground-State Atomic Oxygen-Radical Source Employing an Atmospheric-Pressure Plasma, Appl. Phys. Express. 4 (2011) 116201. doi:10.1143/APEX.4.116201.

[23] H. Hashizume, T. Ohta, T. Mori, S. Iseki, M. Hori, M. Ito, Inactivation Process of Penicillium digitatum Spores Treated with Non-equilibrium Atmospheric Pressure Plasma, Jpn. J. Appl. Phys. 52 (2013) 056202. doi:10.7567/JJAP.52.056202.

[24] H. Hashizume, T. Ohta, K. Takeda, K. Ishikawa, M. Hori, M. Ito, Oxidation mechanism of Penicillium digitatum spores through neutral oxygen radicals, Jpn. J. Appl. Phys. 53 (2014) 010209. doi:10.7567/JJAP.53.010209.

[25] H. Hashizume, T. Ohta, K. Takeda, K. Ishikawa, M. Hori, M. Ito, Quantitative clarification of inactivation mechanism of Penicillium digitatum spores treated with neutral oxygen radicals, Jpn. J. Appl. Phys. 54 (2015) 01AG05. doi:10.7567/JJAP.54.01AG05.

[26] H. Hashizume, T. Ohta, J. Fengdong, K. Takeda, K. Ishikawa, M. Hori, et al., Inactivation effects of neutral 
reactive-oxygen species on Penicillium digitatum spores using non-equilibrium atmospheric-pressure oxygen radical source, Appl. Phys. Lett. 103 (2013) 153708. doi:10.1063/1.4824892.

[27] H. Hashizume, T. Ohta, M. Hori, M. Ito, Growth control of Saccharomyces cerevisiae through dose of oxygen atoms, Appl. Phys. Lett. 107 (2015) 093701. doi:10.1063/1.4929952.

[28] H. Yasuda, M. Hashimoto, M.M. Rahman, K. Takashima, A. Mizuno, States of Biological Components in Bacteria and Bacteriophages during Inactivation by Atmospheric Dielectric Barrier Discharges, Plasma Process. Polym. 5 (2008) 615-621. doi:10.1002/ppap.200800036.

[29] E. Kvam, B. Davis, F. Mondello, A.L. Garner, Nonthermal atmospheric plasma rapidly disinfects multidrug-resistant microbes by inducing cell surface damage., Antimicrob. Agents Chemother. 56 (2012) 2028-36. doi:10.1128/AAC.05642-11.

[30] J.Y. Lee, K.Y. Baik, T.S. Kim, J. Lim, H.S. Uhm, E.H. Choi, Effects of non-thermal plasma on the electrical properties of an erythrocyte membrane, Appl. Phys. Lett. 107 (2015) 113701. doi:10.1063/1.4930872.

[31] M.H. Kang, A. Pengkit, K. Choi, S.S. Jeon, H.W. Choi, D.B. Shin, et al., Differential Inactivation of Fungal Spores in Water and on Seeds by Ozone and Arc Discharge Plasma, PLoS One. 10 (2015) e0139263. doi:10.1371/journal.pone.0139263.

[32] I. Iacovache, F.G. van der Goot, L. Pernot, Pore formation: an ancient yet complex form of attack., Biochim. Biophys. Acta. 1778 (2008) 1611-23. doi:10.1016/j.bbamem.2008.01.026.

[33] A. Hirano-Iwata, M. Niwano, M. Sugawara, The design of molecular sensing interfaces with lipid-bilayer assemblies, TrAC Trends Anal. Chem. 27 (2008) 512-520. doi:10.1016/j.trac.2008.04.006.

[34] R. Tero, Substrate Effects on the Formation Process, Structure and Physicochemical Properties of Supported Lipid Bilayers, Materials. 5 (2012) 2658-2680. doi:10.3390/ma5122658.

[35] D. Huang, T. Zhao, W. Xu, T. Yang, P.S. Cremer, Sensing small molecule interactions with lipid membranes by local pH modulation., Anal. Chem. 85 (2013) 10240-8. doi:10.1021/ac401955t.

[36] Y. Tamba, H. Ariyama, V. Levadny, M. Yamazaki, Kinetic pathway of antimicrobial peptide magainin 2-induced pore formation in lipid membranes., J. Phys. Chem. B. 114 (2010) 12018-26. doi:10.1021/jp104527y.

[37] Y. Mao, Z. Shang, Y. Imai, T. Hoshino, R. Tero, M. Tanaka, et al., Surface-induced phase separation of a sphingomyelin/cholesterol/ganglioside GM1-planar bilayer on mica surfaces and microdomain molecular conformation that accelerates Abeta oligomerization., Biochim. Biophys. Acta. 1798 (2010) 1090-9. doi:10.1016/j.bbamem.2010.03.003.

[38] Y. Shinozaki, A. Tanaka, N. Kasai, K. Torimitsu, K. Sumitomo, Ligand-induced structural changes in a membrane-reconstituted ion channel observed with atomic force microscopy, Appl. Phys. Express. 7 (2014) 027001. doi:10.7567/APEX.7.027001.

[39] P. Svarnas, S.H. Matrali, K. Gazeli, S.G. Antimisiaris, Assessment of Atmospheric-Pressure Guided Streamer (Plasma Bullet) Influence on Liposomes with Different Composition and Physicochemical 
Properties, Plasma Process. Polym. 12 (2015) 655-665. doi:10.1002/ppap.201400218.

[40] P. Svarnas, S.H. Matrali, K. Gazeli, S. Aleiferis, F. Clément, S.G. Antimisiaris, Atmospheric-pressure guided streamers for liposomal membrane disruption, Appl. Phys. Lett. 101 (2012) 264103. doi:10.1063/1.4773201.

[41] M.U. Hammer, E. Forbrig, S. Kupsch, K.-D. Weltmann, S. Reuter, Influence of Plasma Treatment on the Structure and Function of Lipids, Plasma Med. 3 (2013) 97-114. doi:10.1615/PlasmaMed.2014009708.

[42] E.J. Szili, J.W. Bradley, R.D. Short, A "tissue model" to study the plasma delivery of reactive oxygen species, J. Phys. D. Appl. Phys. 47 (2014) 152002. doi:10.1088/0022-3727/47/15/152002.

[43] S. Hong, E.J. Szili, A.T.A. Jenkins, R.D. Short, Ionized gas (plasma) delivery of reactive oxygen species (ROS) into artificial cells, J. Phys. D. Appl. Phys. 47 (2014) 362001. doi:10.1088/0022-3727/47/36/362001.

[44] E.J. Szili, S. Hong, R.D. Short, On the effect of serum on the transport of reactive oxygen species across phospholipid membranes, Biointerphases. 10 (2015) 029511. doi:10.1116/1.4918765.

[45] R. Tero, Y. Suda, R. Kato, H. Tanoue, H. Takikawa, Plasma irradiation of artificial cell membrane system at solid-liquid interface, Appl. Phys. Express. 7 (2014) 077001. doi:10.7567/APEX.7.077001.

[46] Y. Suda, R. Tero, R. Yamashita, K. Yusa, H. Takikawa, Reduction in lateral lipid mobility of lipid bilayer membrane by atmospheric pressure plasma irradiation, Jpn. J. Appl. Phys. 55 (2016) 03DF05. doi:10.7567/JJAP.55.03DF05.

[47] Y. Suda, A. Oda, R. Kato, R. Yamashita, H. Tanoue, H. Takikawa, et al., Computational study of temporal behavior of incident species impinging on a water surface in dielectric barrier discharge for the understanding of plasma-liquid interface, Jpn. J. Appl. Phys. 54 (2015) 01 AF03. doi:10.7567/JJAP.54.01AF03.

[48] E.T. Castellana, P.S. Cremer, Solid supported lipid bilayers: From biophysical studies to sensor design, Surf. Sci. Rep. 61 (2006) 429-444. doi:10.1016/j.surfrep.2006.06.001.

[49] I. Czolkos, A. Jesorka, O. Orwar, Molecular phospholipid films on solid supports, Soft Matter. 7 (2011) 4562. doi:10.1039/c0sm01212b.

[50] R. Tero, G. Sazaki, T. Ujihara, T. Urisu, Anomalous Diffusion in Supported Lipid Bilayers Induced by Oxide Surface Nanostructures., Langmuir. 27 (2011) 9662-9665. doi:10.1021/la201474h.

[51] R. Tero, T. Ujihara, T. Urisu, Lipid bilayer membrane with atomic step structure: supported bilayer on a step-and-terrace TiO2(100) surface., Langmuir. 24 (2008) 11567-11576. doi:10.1021/la801080f.

[52] R. Tero, H. Watanabe, T. Urisu, Supported phospholipid bilayer formation on hydrophilicity-controlled silicon dioxide surfaces, Phys. Chem. Chem. Phys. 8 (2006) 3885. doi:10.1039/b606052h.

[53] S. Lei, R. Tero, N. Misawa, S. Yamamura, L. Wan, T. Urisu, AFM characterization of gramicidin-A in tethered lipid membrane on silicon surface, Chem. Phys. Lett. 429 (2006) 244-249. doi:10.1016/j.cplett.2006.07.091.

[54] Y. Mao, R. Tero, Y. Imai, T. Hoshino, T. Urisu, The morphology of GM1x/SM0.6-x/Chol0.4 planar bilayers supported on SiO2 surfaces, Chem. Phys. Lett. 460 (2008) 289-294. doi:10.1016/j.cplett.2008.05.097. 
[55] R. Tero, T. Ujihara, T. Urisu, Supported lipid bilayer membranes on $\mathrm{SiO} 2$ and TiO2: Substrate effects on membrane formation and shape transformation, Proc. SPIE. 6769 (2007) 67690J-1-12. doi:10.1117/12.733628.

[56] J.F. Nagle, S. Tristram-Nagle, Structure of lipid bilayers, Biochim. Biophys. Acta - Rev. Biomembranes. 1469 (2000) 159-195. doi:10.1016/S0304-4157(00)00016-2.

[57] R. Tero, M. Takizawa, Y.-J. Li, M. Yamazaki, T. Urisu, Lipid membrane formation by vesicle fusion on silicon dioxide surfaces modified with alkyl self-assembled monolayer islands., Langmuir. 20 (2004) 7526-31. doi:10.1021/la0400306.

[58] H.D. Grimes, K.K. Perkins, W.F. Boss, Ozone Degrades into Hydroxyl Radical under Physiological Conditions: A Spin Trapping Study, Plant Physiol. 72 (1983) 1016-1020. doi:10.1104/pp.72.4.1016.

[59] H. Kurita, M. Shimizu, K. Sano, T. Nakajima, H. Yasuda, K. Takashima, et al., Radical reaction in aqueous media injected by atmospheric pressure plasma jet and protective effect of antioxidant reagents evaluated by single-molecule DNA measurement, Jpn. J. Appl. Phys. 53 (2014) 05FR01. doi:10.7567/JJAP.53.05FR01.

[60] T. Shimizu, Y. Iwafuchi, G.E. Morfill, T. Sato, Formation of thermal flow fields and chemical transport in air and water by atmospheric plasma, New J. Phys. 13 (2011) 053025. doi:10.1088/1367-2630/13/5/053025.

[61] C.A.J. van Gils, S. Hofmann, B.K.H.L. Boekema, R. Brandenburg, P.J. Bruggeman, Mechanisms of bacterial inactivation in the liquid phase induced by a remote RF cold atmospheric pressure plasma jet, J. Phys. D. Appl. Phys. 46 (2013) 175203. doi:10.1088/0022-3727/46/17/175203.

[62] A. Nakajima, G. Uchida, T. Kawasaki, K. Koga, T. Sarinont, T. Amano, et al., Effects of gas flow on oxidation reaction in liquid induced by He/O2 plasma-jet irradiation, J. Appl. Phys. 118 (2015) 043301. doi:10.1063/1.4927217.

[63] S.K. Han, M. Kim, Y.H. Park, E.J. Park, J.H. Lee, Effect of lipid peroxidation on the fluidity of erythrocyte ghost and phospholipid liposomal membranes, Arch. Pharm. Res. 15 (1992) 309-316. doi:10.1007/BF02974104.

[64] V. Jarerattanachat, M. Karttunen, J. Wong-ekkabut, Molecular Dynamics Study of Oxidized Lipid Bilayers in NaCl Solution, J. Phys. Chem. B. 117 (2013) 8490-8501. doi:10.1021/jp4040612.

[65] P. Jurkiewicz, A. Olżyńska, L. Cwiklik, E. Conte, P. Jungwirth, F.M. Megli, et al., Biophysics of lipid bilayers containing oxidatively modified phospholipids: Insights from fluorescence and EPR experiments and from MD simulations, Biochim. Biophys. Acta - Biomembranes. 1818 (2012) 2388-2402. doi:10.1016/j.bbamem.2012.05.020.

[66] W. Tai, Y. Yang, H. Lin, C. Huang, Y. Cheng, M. Chen, et al., Interplay between Structure and Fluidity of Model Lipid Membranes under Oxidative Attack, J. Phys. Chem. B. 114 (2010) 15642-15649. doi:10.1021/jp1014719.

[67] J.N. Israelachvili, Intermolecular and Surface Forces, Third Edition, 3rd ed., Academic Press;, 2011. https://www.elsevier.com/books/intermolecular-and-surface-forces/israelachvili/978-0-12-391927-4 (accessed June 3, 2015). 
[68] L. Cwiklik, P. Jungwirth, Massive oxidation of phospholipid membranes leads to pore creation and bilayer disintegration, Chem. Phys. Lett. 486 (2010) 99-103. doi:10.1016/j.cplett.2010.01.010.

[69] L.R.C. Barclay, K.A. Baskin, D. Kong, S.J. Locke, Autoxidation of model membranes. The kinetics and mechanism of autoxidation of mixed phospholipid bilayers, Can. J. Chem. 65 (1987) 2541-2550. doi:10.1139/v87-423.

[70] G.P. Bienert, F. Chaumont, Aquaporin-facilitated transmembrane diffusion of hydrogen peroxide, Biochim. Biophys. Acta - Gen. Subj. 1840 (2014) 1596-1604. doi:10.1016/j.bbagen.2013.09.017.

[71] Y. Saito, K. Nishio, Y. Ogawa, J. Kimata, T. Kinumi, Y. Yoshida, et al., Turning point in apoptosis/necrosis induced by hydrogen peroxide., Free Radic. Res. 40 (2006) 619-30. doi:10.1080/10715760600632552.

[72] B. Haertel, S. Straßenburg, K. Oehmigen, K. Wende, T. von Woedtke, U. Lindequist, Differential Influence of Components Resulting from Atmospheric-Pressure Plasma on Integrin Expression of Human HaCaT Keratinocytes, Biomed Res. Int. 2013 (2013) 1-9. doi:10.1155/2013/761451.

[73] T. Adachi, H. Tanaka, S. Nonomura, H. Hara, S. Kondo, M. Hori, Plasma-activated medium induces A549 cell injury via a spiral apoptotic cascade involving the mitochondrial-nuclear network., Free Radic. Biol. Med. 79 (2015) 28-44. doi:10.1016/j.freeradbiomed.2014.11.014. 
Figure 1

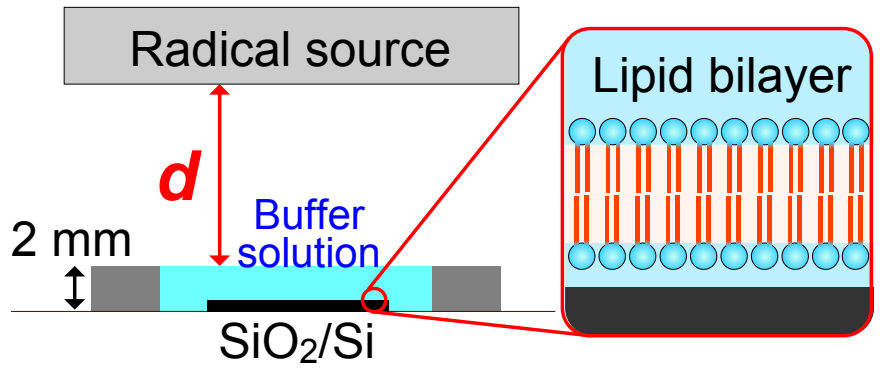


Figure 2
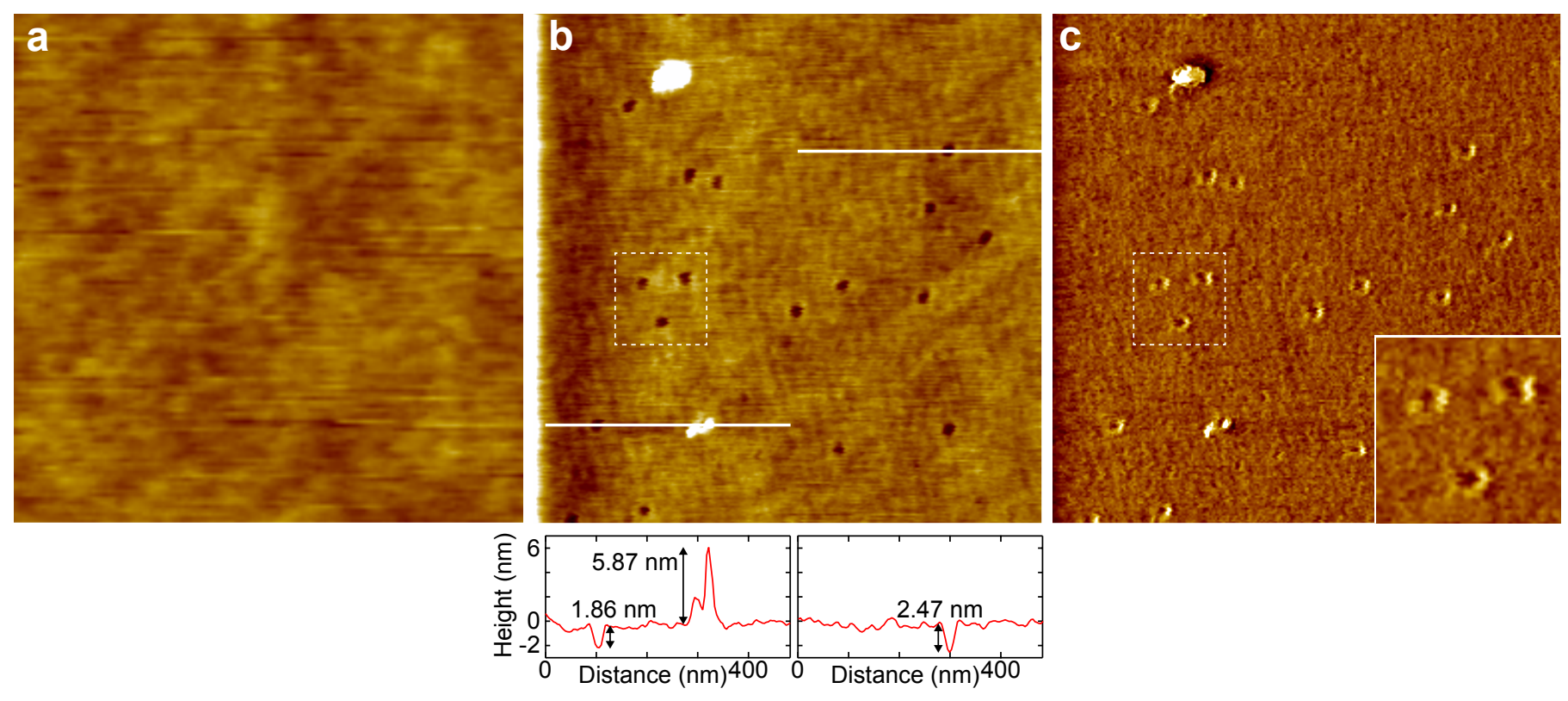

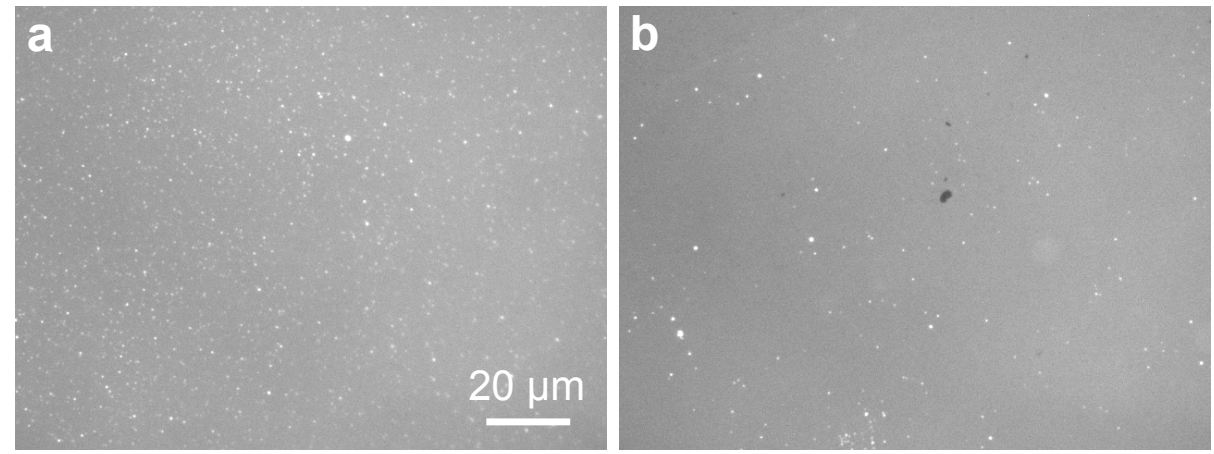

c

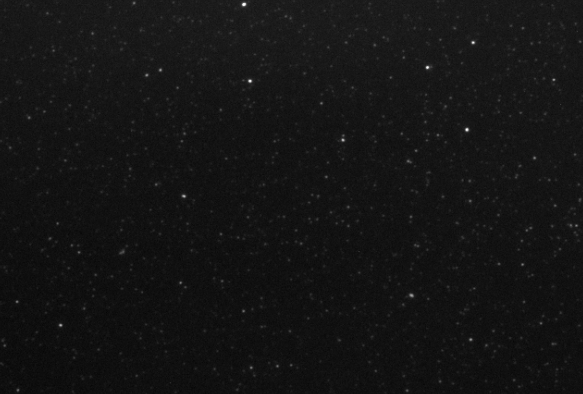

Figure 

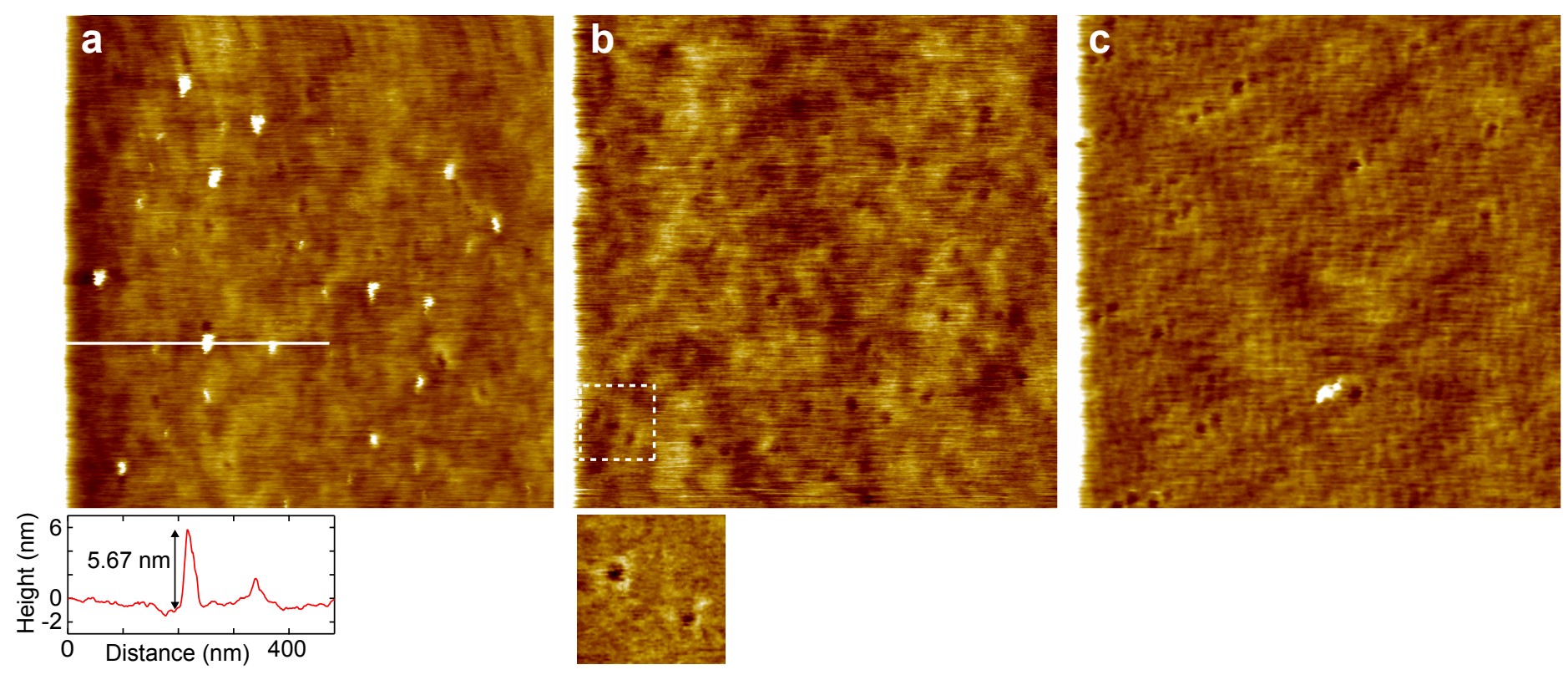

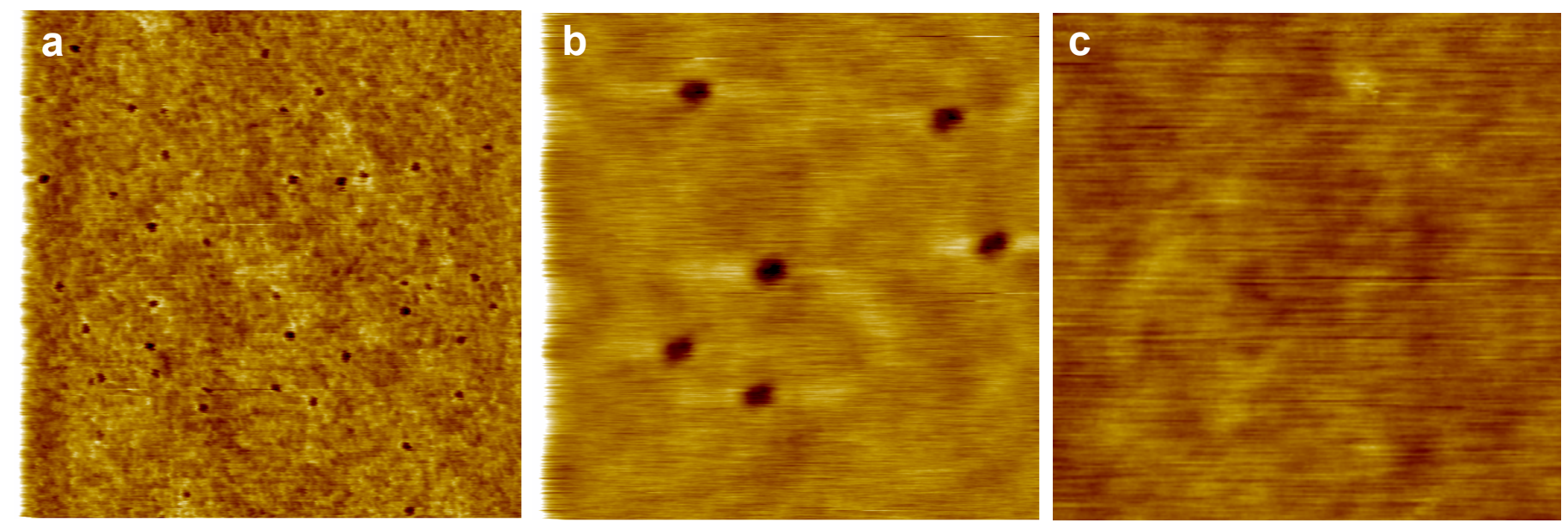

Figure 5 
Figure 6

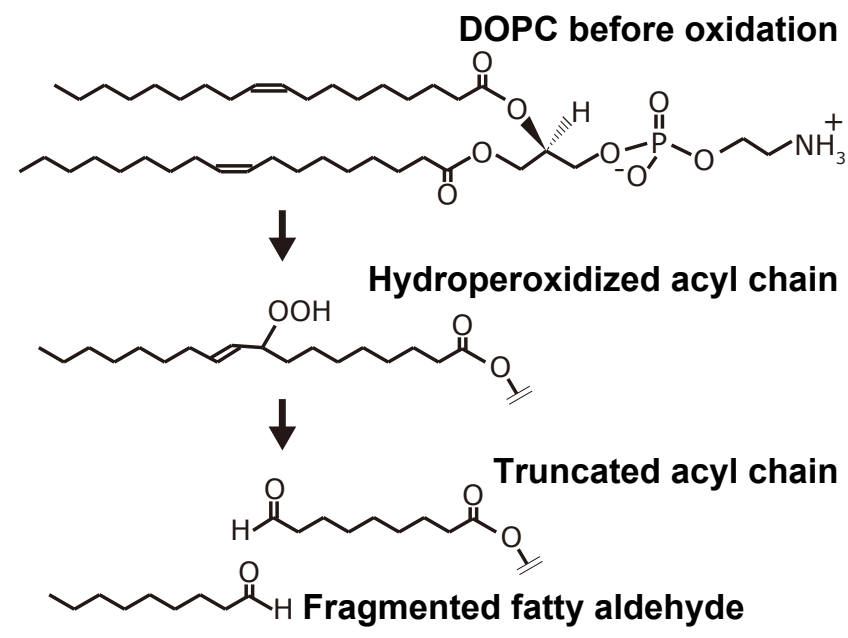


Figure 7

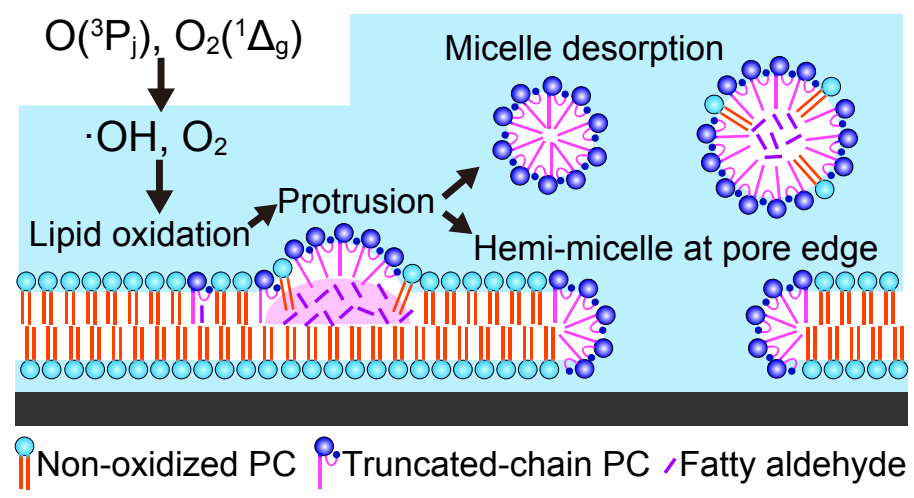




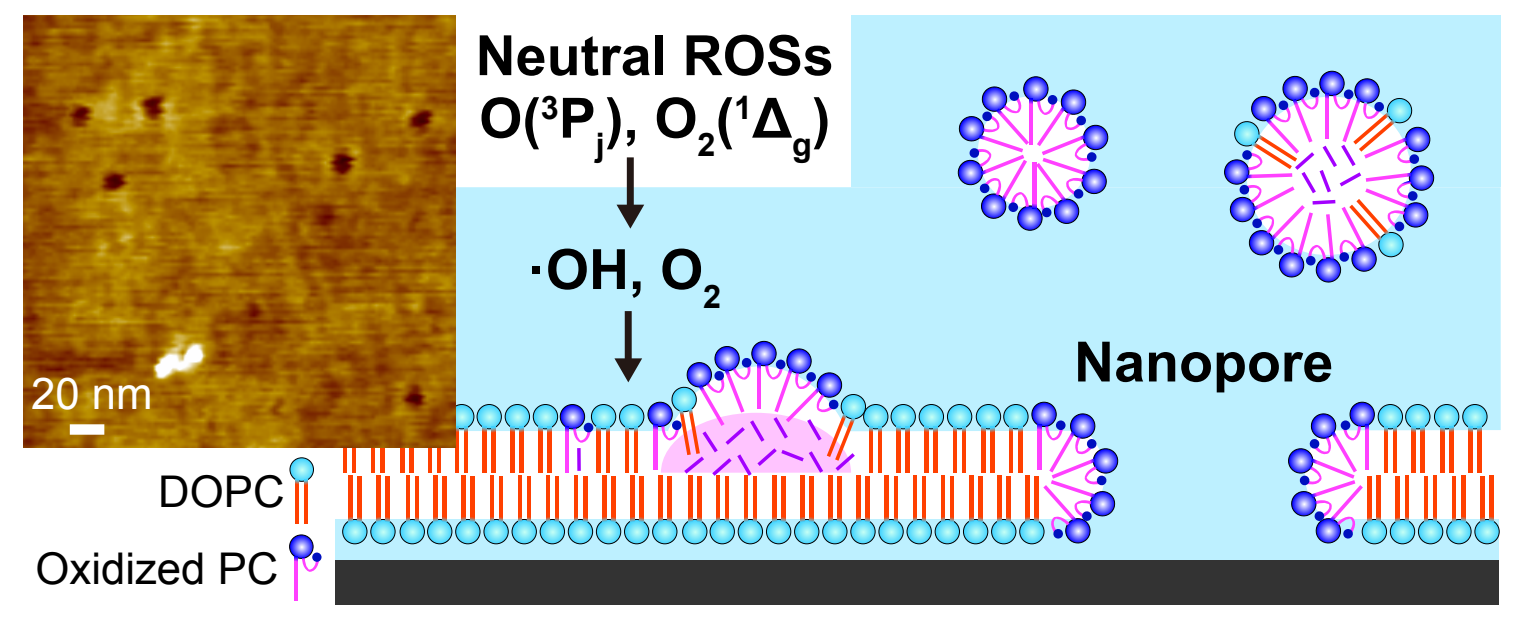

Neutral ROSs

$\mathbf{O}\left({ }^{3} \mathbf{P}_{\mathrm{j}}\right), \mathbf{O}_{2}\left({ }^{1} \Delta_{\mathrm{g}}\right)$

$\mathrm{OH}, \mathrm{O}_{2}$

Nanopore

Oxidized PC

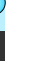

